\title{
Eco-physiological basis of shade adaptation of Camellia nitidissima, a rare and endangered forest understory plant of Southeast Asia
}

\author{
Shengfeng Chai ${ }^{1} \mathbb{1}$, Jianmin Tang ${ }^{1}$, Azim Mallik ${ }^{1,2^{*}}$, Yancai Shi ${ }^{1}$, Rong Zou ${ }^{1}$, Jitao Li ${ }^{1}$ and Xiao Wei ${ }^{{ }^{*}}$
}

\begin{abstract}
Background: Camellia nitidissima, a rare and endangered shrub is narrowly distributed in South China and North Vietnam occurring in forest understory. Their light tolerance mechanism is unclear. We measured photosynthesis and related parameters on 2-years-old cuttings growing at 10,30, 50 and 100\% sunlight. Our research question was: At what light level are C. nitidissima cuttings responding most favorably, and what is the eco-physiological basis for their response to light? We hypothesized that as a forest understory growth of $C$. nitidissima would respond most favorably at low to intermediate light by optimizing photosynthetic activity, and high light will affect photosynthetic functions due to photoinhibition, damage of photosynthetic apparatus and concomitant enzyme activity.
\end{abstract}

Results: With increasing light, the maximum net photosynthetic rate $\left(P_{\mathrm{Nmax}}\right)$ and apparent quantum yield (AQY) decreased, while the light compensation point increased, and light saturation point first increased followed by a decrease. The $P_{\mathrm{Nmax}}$ and AQY under 50 and 100\% sunlight were significantly lower than that under 10 and 30\% sunlight. The chlorophyll fluorescence parameters $F_{m^{\prime}} F_{v}, F_{v} / F_{m}$ all decreased under high light $(>50 \%)$. The contents of chlorophyll a (Chla), chlorophyll b (Chlb), and carotenoid (Car) decreased with increasing light. Relative conductivity, malondialdehyde (MDA) and proline contents in leaves were significantly increased in high light but we found no significant difference in these indices at 10 and $30 \%$ sunlight.

Conclusions: We conclude that C. nitidissima is a shade adapted plant with poor adaptability to high light (> 50\%). The novelty of this research is the demonstration of the eco-physiological basis of its light tolerance (conversely, shade adaptation) mechanisms indicated by decreased photosynthetic activity, chlorophyll fluorescence, Chla, Chlb and Car contents and concomitant increase in relative conductivity, MDA and proline contents at high light causing photoinhibition. For artificial propagation of C. nitidissima we recommend growing cuttings below $30 \%$ sunlight. For in situ conservation of this valuable, rare and endangered shrub it is necessary to protect its natural habitats.

Keywords: Camellia nitidissima, Light gradient, Photosynthetic light response, Chlorophyll fluorescence, Physiology, Photoinhibition

\footnotetext{
*Correspondence: aumallik@hotmail.com; 529513474@qq.com

${ }^{1}$ Guangxi Key Laboratory of Plant Conservation and Restoration

Ecology in Karst Terrain, Guangxi Institute of Botany, Guangxi Zhuang

Autonomous Region and Chinese Academy of Sciences, Guilin 541006,

China

${ }^{2}$ Department of Biology, Lakehead University, Thunder Bay, ON P7B 5E1,

Canada
} 


\section{Background}

Camellia nitidissima (Theaceae) is a rare and endangered evergreen shrub/small tree. It is one of the few Camellia species with yellow flowers. Because of its high aesthetic, cultural and germplasm value it is also called "the Queen of Camellia" [1, 2]. It has been introduced to Japan, Australia, Europe and North America as an ornamental plant and drew attention from horticulturists worldwide as a valuable genetic resource [3, 4]. It has a narrow distribution in Guangxi Province, South China and North Vietnam [5], growing as understory in evergreen broad-leaf forests along moist valley 50-650 $\mathrm{m}$ above sea level [6]. In China, C. nitidissima has been found only in two disjunctive areas in Guangxi Province, (i) at the junction of Fushu, Longan, and Fusui near Nanning city, and (ii) in Fangcheng, south of Mount Shiwan [7]. C. nitidissima is used as a Chinese traditional medicine [1]. Recently tea and other beverages made from its leaves and flowers have been commercialized and sold in China and Southeast Asia [8, 9]. Unfortunately, due to habitat loss and excessive collecting of seedlings in recent decades, its natural populations have declined dramatically. This species is now listed as one of the most endangered plant species and given protection in China [10].

Light is a predominant environmental factor affecting plant growth and development. Therefore, understanding plant response to light has been a long-term focus of plant eco-physiological research [11]. In optimal light conditions, both photosynthetic fixation of $\mathrm{CO}_{2}$ and rate of photosynthesis increase with increased absorption of light energy by chlorophyll, whereas excessive solar radiation suppress photosynthesis and may cause oxidative damage to the photosynthetic system [12-14]. Recent research on eco-physiology of rare and endangered plants emphasizes the study of the relationship between photosynthesis and incident light. Both deep shade and full light greatly reduce survival of English yew seedlings but $30 \%$ light seems to be optimal for its growth and development [15]; the maintenance of this species in European temperate forests depends mainly on selective canopy opening to reduce light competition [16]. Another endangered species Lindera melissifolia is a facultative shade plant. Although it has the ability to adapt to a range of light conditions it grows optimally below $40 \%$ light and hence this level of light has been suggested for its artificial propagation and reintroduction $[17,18]$. The light stress brought by habitat fragmentation has been suggested as an important cause behind the extinction of seven-son flower (Heptacodium miconioides) and the species is adapted to moderate light intensity, 350$716 \mu \mathrm{mol} \mathrm{m}^{-2} \mathrm{~s}^{-1}$ [14]. Growth of Arundinaria gigantea is enhanced with increased light levels, and in this case reduction of overstory canopy has been suggested as a potential management tool for enhancing survival and growth of existing populations of this endangered species [19]. The limited ability of Abies alba saplings to exploit high-light conditions may be a competitive disadvantage in large canopy gaps limiting recruitment of this species to small gaps [20]. All these studies provide scientific basis for experimenting with rare and endangered species to determine their ecophysiological and growth response to light to device methods for ex situ propagation, conservation and recovery of endangered plants.

It has been found that light adaptability of $C$. nitidissima is narrow, and light environment is of critical importance to its survival, growth and development [21, 22]. In its natural habitats $C$. nitidissima grows as a forest understory with $>75 \%$ canopy cover [10]. As removal of upper canopy trees expose them to full sunshine, leaves of $C$. nitidissima turn yellow, branches gradually wither, and the plants eventually die [23]. Wei et al. [24] compared the differences of photosynthetic characteristics in C. nitidissima and its widespread congener C. sinensis. They concluded that $C$. nitidissima is a shade tolerant species, while $C$. sinensis has a wide range of adaptability to light making it more widely distributed. Qi et al. [25] measured photosynthesis light response of $C$. nitidissima in different seasons using 17 year-old plants grown in ex situ conservation habitats. They found that the species has the higher photosynthetic ability in autumn. Because younger seedlings and stem cuttings of $C$. nitidissima are used for artificial propagation it is necessary to test their growth response to varying light conditions. It is also necessary to measure additional physiological parameters to determine what level of light is appropriate for optimal growth and photosynthetic activity of this plant. Despite its rarity, endangered status, conservation value, and high demand for its medicinal and horticultural value the eco-physiological response of this plant to varying light levels has not been studied. It is necessary to understand its adaptability to a range of light conditions and how that is related to its growth. This knowledge will help devise effective methods for horticultural propagation using appropriate shade treatment above the stem cuttings. It will also help identify natural habitats for planting artificially propagated cuttings for restoration. Hence the main objective of this study was to investigate the responses of the photosynthesis and other physiological characteristics of $C$. nitidissima cuttings to a simulated light gradient created by artificial shading and analyze its sensitivity to light in order to provide a theoretical and practical basis for its ex situ conservation, artificial propagation and population recovery. Our specific research question was: At what light level will $C$. nitidissima cuttings respond most favorably, and what is the eco-physiological basis for their response to light? We 
hypothesized that as a forest understory shrub cuttings of $C$. nitidissima would respond most favorably at low to intermediate levels of light by optimizing photosynthetic activity compared to high light; high light (>50\%) will affect photosynthetic functions due to photoinhibition, damage to photosynthetic apparatus and concomitant enzyme activity.

\section{Methods}

\section{Study site}

The experiment was conducted at the Guangxi Institute of Botany $\left(25^{\circ} 11^{\prime} \mathrm{N}, 110^{\circ} 12^{\prime} \mathrm{E}\right.$; $178 \mathrm{~m}$ a.s.l.), Guilin, Guangxi, South China. This region enjoys subtropical monsoon climate. The mean annual temperature is $19.2{ }^{\circ} \mathrm{C}$, average temperature of the hottest and coldest months are 28.4 and $7.7{ }^{\circ} \mathrm{C}$, respectively with extremes of 40 and $-6{ }^{\circ} \mathrm{C}$, the number of months with average temperature above $20^{\circ} \mathrm{C}$ is $6-7$, the annual accumulated temperature above $10{ }^{\circ} \mathrm{C}$ is $5955.3{ }^{\circ} \mathrm{C}$. Annual rainfall is $1854.8 \mathrm{~mm}, 73 \%$ of which falls between April and August. The relative humidity is $78.0 \%$ with distinct wet and dry season. Average annual sunshine is about $1550 \mathrm{~h}$, and days with frost ranges from 9 to 24 .

\section{Experimental material and treatment}

We simulated a gradient of low to high light by filtering natural sunlight using black nylon that allowed 10, 30, 50 and $100 \%$ of full sunlight. Individual 2-years-old stem cuttings of $C$. nitidissima were used in this study. The cuttings were planted in plastic pots $(30 \mathrm{~cm}$ inner diameter and $25 \mathrm{~cm}$ deep) containing $6 \mathrm{~kg}$ of soil (in a mixture of yellow clay, grass ash and pig manure in a ratio of 4:2:1). At the start of the shade treatment the cuttings were 18 to $22 \mathrm{~cm}$ tall each with 6-8 leaves. Eighty uniform potted cuttings were placed in a shade canopy that allowed $10 \%$ sunlight for a month of recovery/adjustment before the start of the experiment. The cuttings were divided randomly into four groups (20 pots/group) and moved to the pre-set shed canopies allowing 10, 30, 50 and $100 \%$ sunlight in early May, 2015. The pots were watered adequately at each dusk and compound fertilizers applied once a month. Photosynthesis and other physiological parameters were measured 2 months after the commencement of the shade treatments when the cuttings were well adjusted to the experimental shade gradient. Additionally, we measured the diurnal variation of photosynthetically active radiation (PAR), air temperature $\left(T_{\mathrm{a}}\right)$ and relative humidity $(\mathrm{RH})$ under each shade canopy at a clear day during the experiment (Fig. 1).

\section{Measurements}

\section{Light response curves}

Light response curves were determined using the LI-6400 portable photosynthesis system (LI-COR, Lincoln, Nebraska, USA). Measurements were made on the upper, mature and fully expanded leaves from four randomly selected individuals in each treatment, each individual measured only once. To fully activate the photosynthetic system, the leaves were put under $400 \mu \mathrm{mol} \mathrm{m}^{-2} \mathrm{~s}^{-1}$ with the red and blue radiation source in the photosynthesis system for $20 \mathrm{~min}$, then photosynthesis with an open air source was measured at flow rate of $500 \mathrm{~cm}^{3} \mathrm{~min}^{-1}$, leaf temperature $28{ }^{\circ} \mathrm{C}, \mathrm{CO}_{2}$ concentration $360 \mu \mathrm{mol} \mathrm{mol}^{-1}$ (controlled by $\mathrm{CO}_{2}$ cylinder), and irradiances 1800,1500 , $1200,1000,800,600,400,300,200,150,100,50,20$, and $0 \mu \mathrm{mol} \mathrm{m}{ }^{-2} \mathrm{~s}^{-1}$ [26]. Each measurement was made for $2 \mathrm{~min}$ at each irradiance level on the upper fully expanded leaves of $C$. nitidissima cuttings in sunny days during 8:30-11:30 am. Maximum photosynthetic rate $\left(P_{\mathrm{N} \max }\right)$, apparent quantum yield (AQY), light saturation point (LSP), and light compensation point (LCP) were obtained by light response curve.

\section{Chlorophyll fluorescence}

Chlorophyll fluorescence was determined using a LI-6400 portable photosynthesis system fitted with a
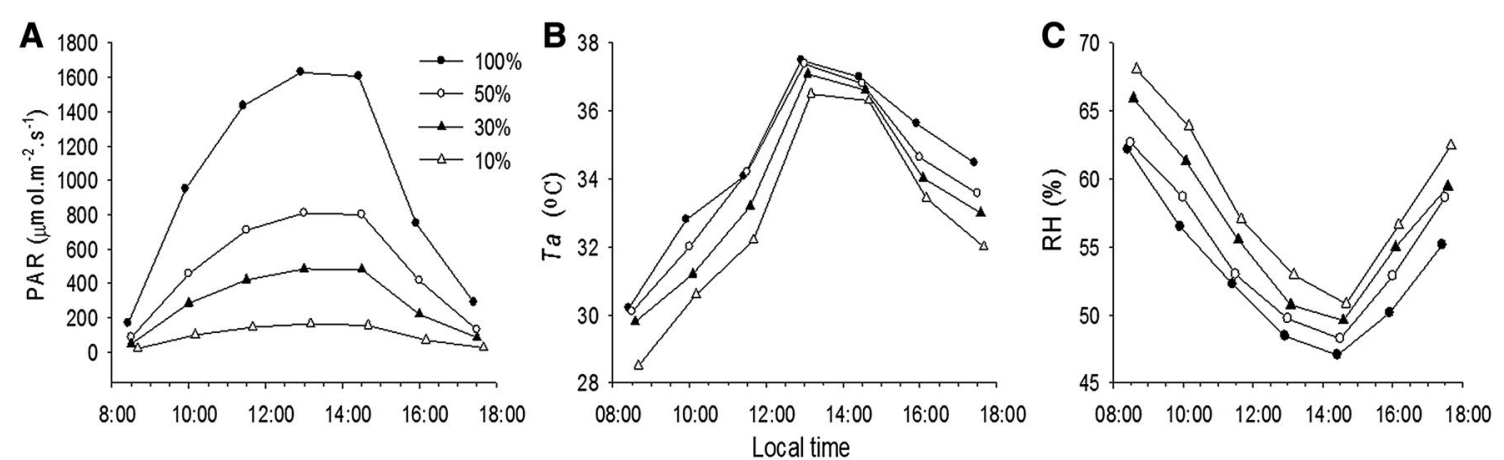

Fig. 1 Diurnal variation of environmental factors under 10, 30, 50, and 100\% sunlight, respectively. A Photosynthetically active radiation (PAR), B air temperature $\left(T_{\mathrm{a}}\right), \mathbf{C}$ relative humidity $(\mathrm{RH})$ 
6400-40 leaf chamber fluorometer. Eight to ten leaves per treatment were selected for the measurements. Minimal fluorescence $\left(F_{0}\right)$ of leaves fully exposed to darkness (more than $30 \mathrm{~min}$ ) was determined under low light, after which the leaf was exposed to a saturate pulsed light $\left(6000 \mu \mathrm{mol} \mathrm{m}{ }^{-2} \mathrm{~s}^{-1}\right.$, duration $\left.0.8 \mathrm{~s}\right)$ to determine the maximum fluorescence $\left(F_{\mathrm{m}}\right)$; then the variable fluorescence $F_{\mathrm{v}}=F_{\mathrm{m}}-F_{0}$ and maximal quantum yield of PSII photochemistry $\left(F_{\mathrm{v}} / F_{\mathrm{m}}\right)$ were calculated. All measurements were taken in the morning (7:00-9:00).

\section{Photosynthetic pigments}

After the photosynthetic measurements, four cuttings per treatment were selected to determine the photosynthetic pigments. Leaf chlorophyll (Chl) and carotenoid (Car) contents were determined following the method of Lichtenthaler [27]. The pigments were extracted with $95 \%$ ethanol, and the absorbance of extracted liquids was recorded at 665 and $649 \mathrm{~nm}$ for Chl, and at $470 \mathrm{~nm}$ for Car in a spectrophotometer (TU1901, Beijing Purkinje General Instrument Co., Ltd., China), based on which the contents of Chla, Chlb, and Car were calculated with formulas: Chla $=13.95 A_{665}-6.88 A_{649}$, Chlb $=24.96$ $A_{649}-7.32 A_{665}, \mathrm{Car}=\left(1000 A_{470}-2.05\right.$ Chla -114.8 Chlb)/245, as well as the ratios of Chla/b and Car/Chl.

\section{Relative conductivity, malondialdehyde and proline contents}

Because high relative conductivity, malondialdehyde (MDA) and proline content indicate damage to cell membrane and oxidative stress we measured these parameters in response to the light gradient [14, 28]. Fresh $1.0 \mathrm{~g}$ leaf samples were minced into small fragments, and incubated under vacuum condition for $15 \mathrm{~min}$, then soaked in a glass tube with $20 \mathrm{~mL}$ distilled water. After $4 \mathrm{~h}$ extraction, the conductivity values were measured using a digital conductivity meter DDS-11A (Shanghai Optical Instrument Factory, China). After that, the samples were boiled for $20 \mathrm{~min}$ and conductivity was measured again after cooling the samples to room temperature. The relative conductivity was expressed as the ratio of the former conductivity to the corresponding latter [29]. Lipid peroxidation was determined by measuring MDA content according to the method of Hodges et al. [30]. First, $0.2 \mathrm{~g}$ fresh leaf tissue was homogenized in $10 \mathrm{~mL} 10 \%$ trichloroacetic acid (w/v). The homogenate was centrifuged at $4000 \times g$ for $10 \mathrm{~min}$, and then $2 \mathrm{~mL}$ of the supernatant were mixed with $2 \mathrm{~mL} 0.67 \%$ 2-thiobarbituric acid $(\mathrm{w} / \mathrm{v})$. The mixture was incubated in boiling water $\left(95-100{ }^{\circ} \mathrm{C}\right)$ for $30 \mathrm{~min}$ and then centrifuged at $4000 \times g$ for $10 \mathrm{~min}$. The absorbance of reaction supernatant was measured at 450,532, and $600 \mathrm{~nm}$, and level of lipid peroxides was calculated following the formula:
$C(\mu \mathrm{mol} / \mathrm{L})=6.45\left(A_{532}-A 600\right)-0.56 A_{450}$. The amount of proline was measured based on the method of Bates et al. [31]. Briefly, $0.2 \mathrm{~g}$ fresh leaf was homogenized in $10 \mathrm{~mL} \mathrm{3 \%}$ aqueous sulfosalicylic acid and filtered through filter paper. Then, $2 \mathrm{~mL}$ of the filtrate was mixed with $2 \mathrm{~mL}$ acid-ninhydrin and $2 \mathrm{~mL}$ glacial acetic acid and heated at $100{ }^{\circ} \mathrm{C}$ for $30 \mathrm{~min}$, then $4 \mathrm{~mL}$ toluene was added to the mixture and the contents of tubes were stirred for $30 \mathrm{~s}$. Absorbance of the red upper phase was measured at $520 \mathrm{~nm}$. A standard curve for proline was constructed to determine the proline concentration in each sample.

\section{Data analyses}

Light response curves were fitted by modified rectangular hyperbola model [32-34].

$$
P_{N}(I)=\frac{\alpha(1-\beta I)}{1+\gamma I} I-R_{\mathrm{d}}
$$

where $P_{\mathrm{N}}$ is net photosynthesis, $I$ is incident photosynthetic photon flux density, $R_{\mathrm{d}}$ is dark respiration, $\alpha$ is initial slope of the curve, $\beta$ and $\gamma$ are coefficients which are independent of $I$.

$$
\begin{aligned}
& P_{\text {Nmax }} \text { was calculated by } P_{N \max }=\alpha\left(\frac{\sqrt{(\beta+\gamma)}-\sqrt{\beta}}{\gamma}\right)^{2}-R_{\mathrm{d}} . \\
& \text { LCP using the model LCP }=\frac{-\left(\gamma R_{\mathrm{d}}-\alpha\right)-\sqrt{\left(\gamma R_{\mathrm{d}}-\alpha\right)^{2}-4 \alpha \beta R_{\mathrm{d}}}}{2 \alpha \beta} . \\
& \text { LSP using the model LSP }=[\sqrt{(\beta+\gamma) / \beta}-1] / \gamma .
\end{aligned}
$$

The apparent quantum yield (AQY) was calculated as the slope of the linear regression of the light response curve below $100 \mu \mathrm{mol} \mathrm{m}^{-2} \mathrm{~s}^{-1}$.

All statistical analyses were performed using the software statistical package SPSS 18.0 (Chicago, IL, USA). We determined what level of light is appropriate for optimal growth and photosynthetic activity of this plant by comparing photosynthetic parameter, chlorophyll fluorescence, photosynthetic pigments, and other physiological parameters of the cuttings grown under the four levels of light. Differences between the treatments were determined by ANOVA followed by Duncan's multiplerange test at the $P<0.05$ level.

\section{Results}

\section{Photosynthetic parameters}

Under the same incident photosynthetic photon flux density, $C$. nitidissima grown under low light showed higher net photosynthesis rate $\left(P_{\mathrm{N}}\right)$ than under high light (Fig. 2). The $P_{\text {Nmax }}$ decreased with increasing light intensity (Table 1), $P_{\mathrm{Nmax}}$ under 30,50 and $100 \%$ sunlight was decreased by $11.29,21.92$ and $38.41 \%$, respectively, compared to that under $10 \%$ sunlight. LCP was increased with increasing light intensity while LSP first increased 


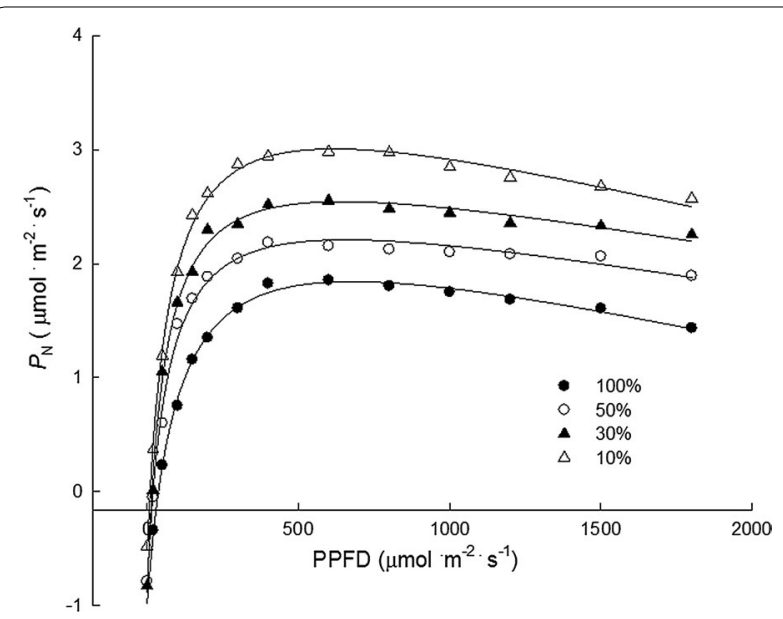

Fig. 2 The photosynthetic light response curves of C. nitidissima grown under 10, 30, 50 and 100\% sunlight, respectively

and then decreased. LCP was increased by $64.57,99.44$ and $278.97 \%$, respectively, compared to that under $10 \%$ sunlight. LSP was highest at $50 \%$ sunlight. The AQY under 50 and $100 \%$ sunlight were significantly lower than that under 10 and $30 \%$ sunlight (Table 1). With increasing light intensity, $C$. nitidissima exhibited serious leaf discoloration. Under 30\% sunlight, there were few brownish spots on leaves but the cuttings grew normally, under $50 \%$ sunlight, many brown spots appeared and under $100 \%$ sunlight, leaves were seriously burned causing defoliation (Fig. 3).

\section{Chlorophyll fluorescence}

With increasing light intensity, $F_{\mathrm{m}}, F_{\mathrm{v}}$ and $F_{\mathrm{v}} / F_{\mathrm{m}}$ were all decreased significantly, while $F_{0}$ first increased followed by a decrease. $F_{\mathrm{m}}, F_{\mathrm{v}}$ and $F_{\mathrm{v}} / F_{\mathrm{m}}$ under 50 and $100 \%$ sunlight were significantly lower than that under $10 \%$ sunlight, but no significant difference was observed between 10 and $30 \%$ sunlight. $F_{0}$ at $100 \%$ sunlight was significantly lower than that under 10,30 and $50 \%$ sunlight, with no significant difference among the latter three treatments (Table 2).

\section{Contents of photosynthetic pigments and their ratios}

Leaf Chla, Chlb, Chla+b and Car contents of C. nitidissima decreased significantly with increasing light

Table 1 Response of gas exchange parameters of $C$. nitidissima grown under 10, 30, 50 and $100 \%$ sunlight

\begin{tabular}{|c|c|c|c|c|}
\hline RI (\%) & 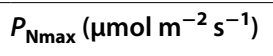 & $\mathrm{AQY}\left(\mu \mathrm{mol} \mu \mathrm{mol}^{-1}\right)$ & $\operatorname{LSP}\left(\mu \mathrm{mol} \mathrm{m} \mathrm{m}^{-2} \mathrm{~s}^{-1}\right)$ & $\operatorname{LCP}\left(\mu \mathrm{mol} \mathrm{m}{ }^{-2} \mathrm{~s}^{-1}\right)$ \\
\hline 10 & $2.91 \pm 0.28 a$ & $0.038 \pm 0.0028 a$ & $537.25 \pm 48.71 c$ & $9.89 \pm 1.06 c$ \\
\hline 30 & $2.58 \pm 0.23 a b$ & $0.037 \pm 0.0031 a$ & $706.57 \pm 51.41 a$ & $16.28 \pm 2.05 b$ \\
\hline 50 & $2.27 \pm 0.21 b$ & $0.027 \pm 0.0025 b$ & $750.25 \pm 52.83 a$ & $19.73 \pm 2.65 b$ \\
\hline 100 & $1.79 \pm 0.17 c$ & $0.024 \pm 0.0022 b$ & $619.50 \pm 50.65 b$ & $37.50 \pm 3.43 a$ \\
\hline
\end{tabular}

Values are mean \pm SD. Small letters indicate significant difference in mean value $( \pm$ SD) of the parameters under different light levels $(P<0.05)$

$R /$ relative irradiance, $P_{\mathrm{Nmax}}$ maximum net photosynthetic rate, $A Q Y$ apparent quantum yield, $L S P$ light saturation point, $L C P$ light compensation point
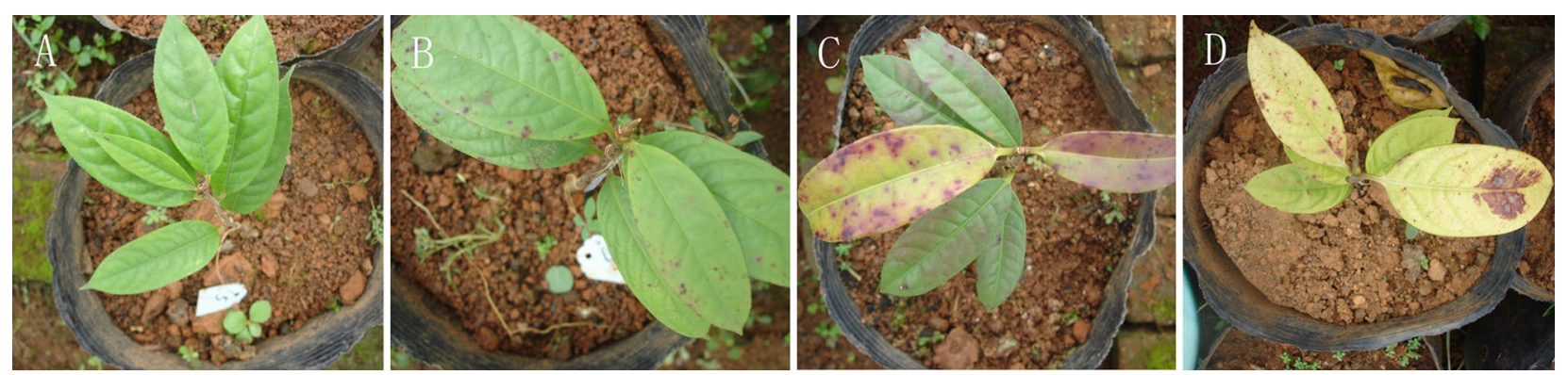

Fig. 3 Seedling growth and leaf morphology of C. nitidissima grown under 10\% (A), 30\% (B), 50\% (C) and 100\% (D) sunlight, respectively

Table 2 Chlorophyll fluorescence characteristics of $C$. nitidissima grown under 10, 30, 50 and $100 \%$ sunlight

\begin{tabular}{lllll}
\hline $\mathbf{R I}(\%)$ & $\boldsymbol{F}_{\mathbf{0}}$ & $\boldsymbol{F}_{\mathbf{m}}$ & $\boldsymbol{F}_{\mathbf{v}}$ & $\boldsymbol{F}_{\mathbf{v}} / \boldsymbol{F}_{\mathbf{m}}$ \\
\hline 10 & $182.07 \pm 7.72 \mathrm{a}$ & $940.67 \pm 40.60 \mathrm{a}$ & $758.60 \pm 36.85 \mathrm{a}$ & $0.806 \pm 0.008 \mathrm{a}$ \\
30 & $193.37 \pm 6.91 \mathrm{a}$ & $885.89 \pm 38.66 \mathrm{a}$ & $692.51 \pm 36.96 \mathrm{a}$ & $0.782 \pm 0.010 \mathrm{ab}$ \\
50 & $174.84 \pm 31.47 \mathrm{a}$ & $701.42 \pm 68.17 \mathrm{~b}$ & $526.58 \pm 49.43 \mathrm{~b}$ & $0.751 \pm 0.032 \mathrm{~b}$ \\
100 & $103.27 \pm 21.95 \mathrm{~b}$ & $272.50 \pm 55.42 \mathrm{c}$ & $169.23 \pm 34.74 \mathrm{c}$ & $0.621 \pm 0.023 \mathrm{c}$ \\
\hline
\end{tabular}

Small letters indicate significant difference in mean value $( \pm \mathrm{SD})$ of the parameters under different light levels $(P<0.05)$ 
intensity. Chla contents in plants grown under 30, 50 and $100 \%$ sunlight were decreased by $18.53,37.66$ and $81.47 \%$, Chlb contents decreased by $28.26,31.03$ and $80.83 \%$, Chla+b contents decreased by $21.78,35.45$ and $81.25 \%$, and Car contents decreased by $2.50,10.00$ and $41.87 \%$, respectively, compared to that in cuttings grown under $10 \%$ sunlight (Fig. 4A). The ratio of Car/Chl showed an increasing trend with increasing light, while Chla/b showed no significant difference among the light treatments (Fig. 4B).

\section{Relative conductivity, MDA and proline contents}

With increasing light intensity there was a significant increase in relative conductivity and MDA contents of C. nitidissima. These two indices under 50 and $100 \%$ sunlight were significantly higher than that under $10 \%$
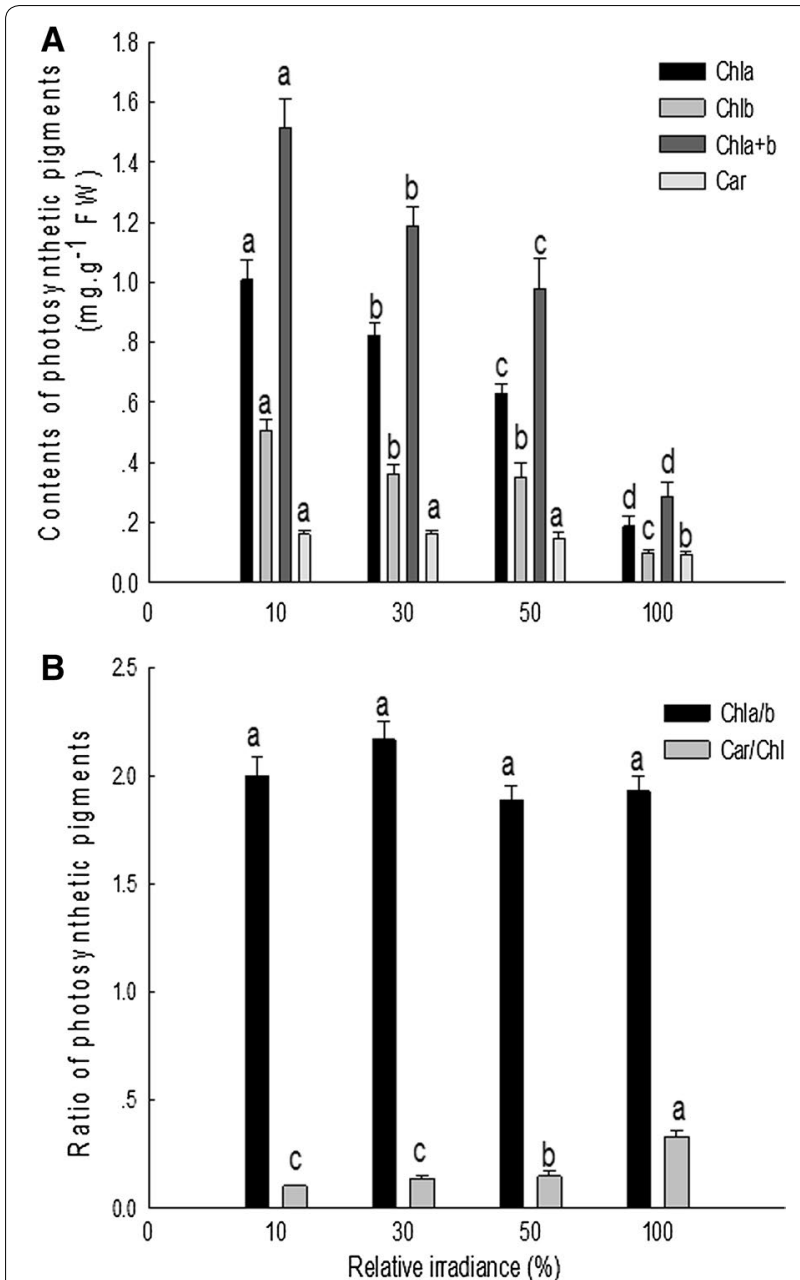

Fig. 4 Contents $(\mathbf{A})$ and ratio (B) of photosynthetic pigments in leaves of $C$. nitidissima grown under 10,30, 50 and 100\% sunlight, respectively. Different letters above the histograms indicate significant difference among different light levels $(P<0.05)$ sunlight. However, there was no significant difference in these parameters between cuttings grown under 10 and $30 \%$ sunlight (Fig. 5A, B). Proline contents in plants grown under 30,50 and $100 \%$ sunlight were $1.22,1.74$ and 2.63 times than those under 10\% sunlight (Fig. 5C).

\section{Discussion}

Light is a primary energy source necessary for photosynthesis, growth and development of plants. However, when light absorbed by leaves cannot be optimally exploited or dissipated, plants suffer from light stress. This may cause reduction in photosynthetic function, photoinhibition or even light oxidation, leading to destruction of
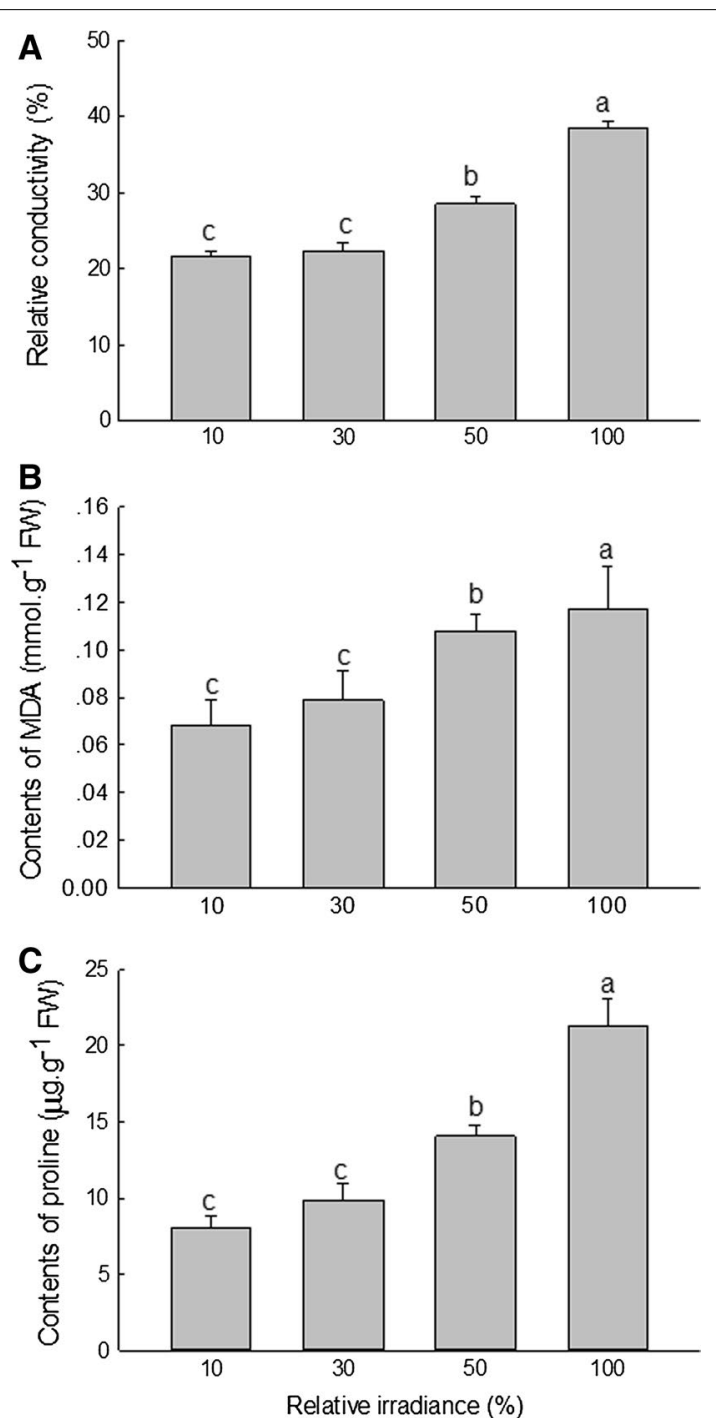

Fig. 5 The relative conductivity $(\mathbf{A}), \operatorname{MDA}(\mathbf{B})$, and proline $(\mathbf{C})$ contents in leaves of $\boldsymbol{C}$. nitidissima grown under 10,30,50, and 100\% sunlight, respectively. Different letters above the histograms indicate significant difference among different light levels $(P<0.05)$ 
photosynthetic apparatus [13, 35]. In this study, we found that $P_{\mathrm{Nmax}}$ of C. nitidissima was $2.91 \mu \mathrm{mol} \mathrm{m}^{-2} \mathrm{~s}^{-1}$, LSP $537.25 \mu \mathrm{mol} \mathrm{m}{ }^{-2} \mathrm{~s}^{-1}$, and LCP $9.89 \mu \mathrm{mol} \mathrm{m}^{-2} \mathrm{~s}^{-1}$ under $10 \%$ sunlight, significantly lower than its widespread congener $C$. sinensis $\left(P_{\mathrm{Nmax}}=10.16 \mu \mathrm{mol} \mathrm{m} \mathrm{m}^{-2} \mathrm{~s}^{-1}\right.$, LSP $=768.00 \mu \mathrm{mol} \quad \mathrm{m}^{-2} \mathrm{~s}^{-1}$, and

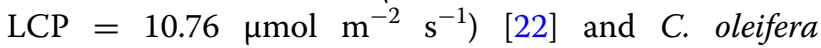
$\left(P_{\mathrm{N} \max }=9.71 \mu \mathrm{mol} \mathrm{m}{ }^{-2} \mathrm{~s}^{-1}, \mathrm{LSP}=1427.00 \mu \mathrm{mol} \mathrm{m}^{-2} \mathrm{~s}^{-1}\right.$, and LCP $=19.60 \mu \mathrm{mol} \mathrm{m}^{-2} \mathrm{~s}^{-1}$ ) [36], indicating that it is a shade adapted plant responding negatively to high light, which supports our hypothesis.

Leaf-level photosynthetic characteristics have been widely used as a tool for detecting environmental stress and for determining growth conditions suitable for different plants [37]. In this study we found that $P_{\mathrm{N} \max }$ of $C$. nitidissima decreased by $11.29,21.92$ and $38.41 \%$, respectively, under 30,50 and $100 \%$ sunlight compared to $10 \%$ sunlight, indicating that photosynthesis was inhibited under high light. Because of decreased chlorophyll content under high light the leaves capture less light. High light may also cause damage to PSII structure, reduce rubisco enzyme activity, increase dark-respiration and photorespiration, which in turn may lead to decreased photosynthetic rate [38]. This result was similar to other shade tolerant plants showing reduced photosynthetic capacity in high light; but there are also some differences: The $P_{\mathrm{Nmax}}$ of $C$. nitidissima was highest in low light (10\% sunlight) while other shade tolerant plants showed highest $P_{\mathrm{Nmax}}$ in medium light (30-50\% sunlight) [39-41], indicating that C. nitidissima appears to be an obligatory shade species with limited acclimation ability to high light conditions [42-44]. AQY is an important parameter to reveal photochemical efficiency, plants grown without environmental stress, the AQY range is $0.03-0.05 \mu \mathrm{mol} \mu \mathrm{mol}^{-1}$ [45]. In our experiment, the AQY of the cuttings grown under 50 and $100 \%$ sunlight were both lower than 0.03 , indicating that $C$. nitidissima grown under these two light levels were subjected to some degree of photoinhibition. In this study, we found an increase of $1.65 \times, 1.99 \times$, and $3.79 \times$ under 30,50 , and $100 \%$ sunlight compared with $10 \%$ sunlight for LCP of $C$. nitidissima. The elevated LCP may be attributed to lower chlorophyll content per unit leaf area and higher dark and light respiration under high light, which resulted in weakened light-harvesting capability and increased carbon assimilation. This is consistent with many other plants whose LCPs were found to increase with increasing irradiance $[15,46]$. In our study, with increasing light intensity, the LSP first increased followed by a decrease, which indicates that $C$. nitidissima has poor adaptability to high light, unlike sun plants having increased LSP with increasing light intensity $[47,48]$. These and other results discussed below also support our hypothesis.
Measurement of chlorophyll fluorescence is a noninvasive, rapid, and quantitative method of assessing the properties of photosynthetic apparatus and the extent to which plants are affected by different types of environmental stress $[49,50]$. In this experiment, with increasing light intensity, $F_{0}$ values first increased followed by a decline. The $F_{0}$ value increase under $30 \%$ sunlight may be related to inactivation of PSII reaction centers, while its decline under 50 and $100 \%$ sunlight may be predominantly attributed to decreased chlorophyll content. $F_{\mathrm{m}}$ and $F_{\mathrm{v}}$ of $C$. nitidissima decreased significantly under 50 and $100 \%$ sunlight compared to $10 \%$ sunlight, indicating the inactivation and/or damage to PSII center complex under high light [51]. The $F_{\mathrm{v}} / F_{\mathrm{m}}$ is widely used as an indicator of photoinhibition [52, 53]. Under normal physiological conditions, the $F_{\mathrm{v}} / F_{\mathrm{m}}$ values of the vast majority of $\mathrm{C}_{3}$ plants range between 0.8 and 0.84 . When the $F_{\mathrm{v}} / F_{\mathrm{m}}$ value of a plant is below this range, the plant is exposed to environmental stress $[54,55]$. In this experiment, the $F_{\mathrm{v}} / F_{\mathrm{m}}$ of $C$. nitidissima under 50 and $100 \%$ sunlight were 0.751 and 0.621 , respectively, indicating that the cuttings grown under these two light levels suffered from long-term photoinhibition. The photosynthetic apparatus presumably absorbed excessive light, resulting in the inactivation or impairment of the PSII reaction centers [41]. This result is consistent with the shade plants Eugenia uniflora and Lasianthus attenuates, the $F_{\mathrm{v}} / F_{\mathrm{m}}$ of these plants decreased significantly without complete recovery for a long time when they are transferred from shade to high light $[44,53]$. However, the $F_{\mathrm{v}} / F_{\mathrm{m}}$ value under $30 \%$ sunlight was close to 0.8 , which suggests that the PSII reaction center functioned normally and the level of photoinhibition was not high.

Chlorophyll absorbs light energy in photosynthesis and chlorophyll content is directly related to rate of photosynthesis [56]. Changes in the Chla/b ratio are related to the balance of light absorption capacity of photosystems [57]. Car/Chl ratio reflects the relationship between light absorption and light damage protection in plants [58]. In this experiment, Chl content (Chla, Chlb, and Chla+b) of $C$. nitidissima decreased significantly with increasing light intensity. Under $100 \%$ sunlight, the contents of Chla, Chlb and Chla+b all decreased more than $80 \%$ than those in $10 \%$ sunlight, which was significantly higher than in Tetrastigma hemsleyanum and Cypripedium guttatum [41, 59], causing Chl bleaching. Such high light may seriously impair or totally inactivate the photosynthetic system. These results may partly explain the low photosynthetic rates of $C$. nitidissima grown under high light. Typically, plants grown in high light have higher $\mathrm{Chla} / \mathrm{b}$ ratio than those in low light [59]. Increased Chl $\mathrm{a} / \mathrm{b}$ ratios are in turn, associated with decrease in the size of the PSII light-harvesting antenna, and changes in 
Rubisco [60]. However, we found no significant difference in Chla/b under different light levels, meaning that C. nitidissima cannot adjust the relative contents of Chla and Chlb to acclimate in high light. It is possible that the increased Car/Chl ratio under high light decreased light absorption in leaves to protect the photosynthetic apparatus from light damage, a protection mechanism to cope with high light stress.

An increase in relative conductivity indicates damage to cell function and results from decomposition of cell membranes and infiltration of metal ions as consequence of stress [61]. The content of MDA, a product of lipid peroxidation, has been considered as an indicator of oxidative damage [62]. In this study, the relative conductivity and MDA contents of leaves under 50 and 100\% sunlight were both significantly higher than those grown under $10 \%$ sunlight, which indicate that high light caused damage to the membrane system of $C$. nitidissima leaves, and photo-oxidation might have occurred. This response is similar to $H$. miconioides and Monimopetalum chinense which have much elevated relative conductivity and MDA content of leaves under high light $[14,40]$. Under $30 \%$ sunlight, these two values were not significantly higher than that under $10 \%$ sunlight, which indicate that there was no oxidative damage at this level of light. These results are further substantiated by the high proline contents at 50 and $100 \%$ sunlight. The lack of acclimation capacity of $C$. nitidissima to increasing light is further supported by the early senescence of its leaves. As light intensity increased, leaf color changed from dark green to light green to yellow green, and leaf burning was clearly visible. Under $50 \%$ sunlight, many brown spots appeared and, under $100 \%$ sunlight, leaves were seriously burned and abscised.

In its natural habitats $C$. nitidissima grows in valleys and streamsides in shady and moist evergreen broadleaf forests. Due to anthropogenic disturbance and environmental deterioration, its habitat has been destroyed and continuously fragmented. An altered microclimatic environment could directly influence plant growth and recruitment $[63,64]$. One important consequence of habitat fragmentation is increased exposure of understory plants to light. Our results demonstrate that $C$. nitidissima has limited acclimation potential to high light, and increasing irradiance has a negative effect on its physiological functions, growth and survival. The changes in microclimate under fragmented habitats also include higher air and soil temperature, higher evaporation and desiccation, lower relative humidity and soil moisture than forest interiors, all causing drought stress $[65,66]$. As $C$. nitidissima is a drought intolerant plant [67], these high light-mediated environmental stresses are contributing to further endangerment of this species. In natural conditions $C$. nitidissima grows under evergreen broadleaf forests with light intensity less than $3 \%$ full sunlight [68]. Although C. nitidissima can grow normally below $30 \%$ sunlight in experimental condition, we do not recommend reducing the overstory canopy for in situ conservation of this species because that will increase competition from other plants that grow optimally under medium light intensity. For artificial propagation we recommend using shade structures that will allow 10-20\% sunlight above the cuttings.

\section{Conclusions}

Based on our results, we conclude that $C$. nitidissima is a shade adapted plant with poor adaptability to high light environment. The plant showed no obvious photoinhibition under $30 \%$ sunlight, while under 50 and $100 \%$ sunlight, respectively, it experienced serious photoinhibition and the photosynthetic apparatus was damaged likely due to photo-oxidation. This is indicated by decreased $P_{\text {Nmax }}$, AQY, $F_{\mathrm{m}}, F_{\mathrm{v}}, F_{\mathrm{v}} / F_{\mathrm{m}}$, Chla, Chlb, Car contents and concomitant increase in relative conductivity, MDA and proline contents of leaves at high light (50 to 100\%). The novelty of this research is that we demonstrate the ecophysiological basis of light tolerance (conversely, shade adaptation) mechanisms in C. nitidissima. For artificial propagation of cuttings of this plant we recommend growing cuttings below $30 \%$ sunlight. For in situ conservation of this valuable, rare and endangered shrub it is necessary protect its natural habitats.

\section{Abbreviations \\ PPFD: photosynthetic photon flux density; $P_{\mathbb{N}}$ : net photosynthetic rate; PAR: photosynthetically active radiation; $T_{\mathrm{a}}$ : air temperature; $\mathrm{RH}$ : relative humid- ity; LCP: light compensation point; LSP: light saturation point; AQY: apparent quantum yield; $P_{\text {Nmax }}$ : photosynthetic rate at irradiation saturation; $F_{0}:$ minimal fluorescence; $F_{v}$ : variable fluorescence; $F_{m}$ : maximum fluorescence; $F_{v} / F_{m}$ : maximum quantum yield of PSIl; Chl: chlorophyll; Car: carotenoids; MDA: malondialdehyde.}

\section{Authors' contributions}

SFC performed the experiment and wrote the first draft of manuscript. XW designed the experiment. JMT, YCS and JTL helped in conducting the experiment, RZ helped in data analysis. AM thoroughly revised and reformatted the manuscript making it ready for submission during his tenure at the Guangxi Institute of Botany as a Distinguished Foreign Expert. AM and SFC revised the manuscript following peer-review and responded to reviewers' comments. All authors read and approved the final manuscript.

\section{Acknowledgements}

Not applicable.

Competing interests

The authors declare that they have no competing interests.

Availability of data and materials

All data generated or analyzed during this study are included in this published article.

Consent for publication

Not applicable. 
Ethics approval and consent to participate

Not applicable.

\section{Funding}

This work was supported by the National Natural Science Foundation of China (31660092), Guangxi Natural Science Foundation Program (2015GXNSFBAA139089, 2016GXNSFBAA380122), Special Project on Innovation Driven Development of Guangxi (Guike-AA17204056-1), and The Fourth Batch of Distinguished Experts of Guangxi Zhuangzu Autonomous Region.

\section{Publisher's Note}

Springer Nature remains neutral with regard to jurisdictional claims in published maps and institutional affiliations.

Received: 20 June 2017 Accepted: 17 January 2018

Published online: 07 February 2018

\section{References}

1. Liang SY. Yellow Camellias. Beijing: Chinese Forestry Press; 1993

2. Wei X, Wei JQ, Cao HL, Li F, Ye WH. Genetic diversity and differentiation of Camellia euphlebia (Theaceae) in Guangxi, China. Ann Bot Fennici. 2005:42:365-70.

3. Nishimoto SI, Hashimoto F, Shimizu K, Sakata Y. Petal coloration of interspecific hydrids between Camellia chysantha $\times$ C. japonica. J Jpn Soc Hortic Sci. 2008;73:189-91.

4. Tang SQ, Bin XY, Wang L, Zhong Y. Genetic diversity and population structure of yellow Camellia (Camellia nitidissima) in China as revealed by RAPD and AFLP markers. Biochem Genet. 2006;44:449-61.

5. Chang HT, Ren SX. Flora reipublicae popularis sinicae, vol. 49. 3rd ed. Beijing: Science Press; 1998. p. 101-12.

6. Wei X, Jiang YS, Jiang SY, Qi XX, Xiong ZC, Ye WH, Wang ZM. Photosynthetic characteristics of an endangered species Camellia nitidissima and its widespread congener Camellia sinensis. Photosynthetica. 2008;46(2):312-4.

7. Su ZM, Mo XL. Geographic distribution of Camellia section Chrysantha from China. Guihaia. 1988;8:75-81.

8. Qin XM, Ning CE, Yang H. Study on the new extracting technology in medicinal ingredients of Camellia nitidissima. Sci Tech Food Ind. 2005;26(10):122-4.

9. Peng $X$, Yu DY, Feng BM, Tang L, Wang YQ, Shi LY. Chemical constituents from the flowers of Camellia nitidissima. Guihaia. 2011;31(4):550-3.

10. Fu LG. China red date book of plants, vol. 1. Beijing: Science Press; 1992.

11. Zhang WF, Fan DY, Xie ZQ, Jiang XH. The seasonal photosynthetic responses of seedlings of the endangered plant Cathaya argyrophylla to different growth light environments. Biodivers Sci. 2005;13(5):387-97.

12. Osmond CB. What is photoinhibition? Some insights from comparisons of shade and sun plants. In: Bake NR, Bowyer JR, editors. Photoinhibition of photosynthesis from molecular mechanisms to the field. Oxford: Bios Scientific Publisher; 1994. p. 1-24.

13. Valladares F, Pearcy RW. Interactions between water stress, sun-shade acclimation, heat tolerance and photoinhibition in the sclerophyll Heteromeles arbutifolia. Plant Cell Environ. 1997;20:25-36.

14. Liu P, Yang YS, Xu GD, Hao CY. Physiological response of rare and endangered seven-son-flower (Heptacodium miconioides) to light stress under habitat fragmentation. Environ Exp Bot. 2007;57:32-40.

15. Iszkuło G. Success and failure of endangered tree species: low temperatures and low light availability affect survival and growth of european yew (taxus baccata L.) seedlings. Pol J Ecol. 2010;58:259-71.

16. Linares JC. Shifting limiting factors for population dynamics and conservation status of the endangered English yew (Taxus baccata L., Taxaceae). Forest Ecol Manag. 2012. https://doi.org/10.1016/j.foreco.2012.11.009.

17. Aleric KM, Kirkman LK. Growth and photosynthetic responses of the federally endangered shrub, Lindera melissifolia (Lauraceae), to varied light environments. Am J Bot. 2009:92(4):682-9.

18. Lockhart BR, Gardiner ES, Stautz T, Leininger TD. Development and plasticity of endangered shrub Lindera melissifolia (Lauraceae) seedlings under contrasting light regimes. Plant Spec Biol. 2012;27:30-45.
19. Cirtain MC, Franklin SB, Pezeshki SR. Effect of Light Intensity on Arundinaria gigantean Growth and Physiology. Castanea. 2009;74(3):236-46.

20. Grassi G, Bagnaresi U. Foliar morphological and physiological plasticity in Picea abies and Abies alba saplings along a natural light gradient. Tree Physiol. 2000;21:959-67.

21. Yang QH, Li XQ, Yang HS, Wei X, Yin XJ. Photosynthetic ecophysiological characteristics of Camellia nitidissima seedlings. J Beijing For Univ. 2010;32(2):57-63.

22. Wei $X, C a o ~ H L$, Jiang YS, Ye WH, Ge XJ, Li F. Population genetic structure of Camellia nitidissima (Theaceae) and conservation implications. Bot Stud. 2008:49:147-53.

23. Su ZM. A preliminary study on the population ecology of Camellia sect. nitidissima. Guangxi Sci. 1994;1(1):31-6.

24. Wei $X$, Jiang YS, Wei JQ, Chen ZY, Wang ML, Zhao RF. Investigation on the geographical distribution and habitat of Camellia nitidissima. Ecol Environ. 2007;16(3):895-9.

25. Qi XX, Jiang YS, Wei X, Tang H, Xiong ZC, Ye WH, Wang ZM. Photosynthetic characteristic of an endangered species Camellia nitidissima and its conservation implications. Pak J Bot. 2012;44:327-31.

26. Mallik AU, Wang JR, Siegwart-Collier LS, Roberts BA. Morphological and ecophysiological responses of sheep laurel (Kalmia angustifolia L.) to shade. Forestry. 2012:85:513-22.

27. Lichthenthaler HK. Chlorophylls and carotenoids: pigments of photosynthetic biomembranes. In: Colowick SP, Kaplan NO, editors. Methods in enzimology, vol. 148. San Diego: Academic Press; 1987. p. 350-82.

28. Osório ML, Osório J, Romano A. Photosynthesis, energy partitioning, and metabolic adjustments of the endangered Cistaceae species Tuberaria major under high temperature and drought. Photosynthetica. 2013:51(1):75-84.

29. Zhang B, Jia D, Gao ZQ, Dong Q, He LH. Physiological responses to low temperature in spring and winter wheat varieties. J Sci Food Agric. 2016;96:1967-73

30. Hodges DM, Delong JM, Forney CF, Prange RK. Improving the thiobarbituric acid-reactive-substances assay for estimating lipid peroxidation in plant tissues containing anthocyanin and other interfering compounds. Planta. 1999;207:604-11.

31. Bates LS, Waldren RP, Tear ID. Rapid determination of free proline for water stress studies. Plant Soil. 1973;156:205-7.

32. Ye ZP. A new model for relationship between irradiance and the rate of photosynthesis in Oryza sativa. Photosynthetica. 2007:45(4):637-40.

33. Wargent JJ, Elfadly EM, Moore JP, Paul ND. Increased exposure to UV-B radiation during early development leads to enhanced photoprotection and improved long-term performance in Lactuca sativa. Plant Cell Environ. 2011:34:1401-13.

34. Xu WZ, Deng XP, Xu BC. Effects of water stress and fertilization on leaf gas exchange and photosynthetic light-response curves of Bothriochloa ischaemum L. Photosynthetica. 2013;51(4):603-12.

35. Lambers H, Chappin FS, Pons TL. Plant physiological ecology. New York: Springer-Verlag; 1998

36. Yuan J, Yuan DY, Tan XF, Zou F, Xiao SX. Comparative study on photosynthetic characteristic of 5 Camellia oleifera clones in Hainan province. $J$ Cent South Univ For Technol. 2017;37:1-6.

37. Pastenes C, Pimentel P, Lillo J. Leaf movements and photoinhibition in relation to water stress in field-grown beans. J Exp Bot. 2004;56:425-33.

38. Li ZR, Wakao S, Fischer BB, Niyogi KK. Sensing and responding to excess light. Annu Rev Plant Biol. 2009;60:239-60.

39. Naramoto M, Katahata S, Mukai Y, Kakubari Y. Photosynthetic acclimation and photoinhibition on exposure to high light in shade-developed leaves of Fagus crenata seedlings. Flora. 2006;201:120-6.

40. Hao CY, Fan R, Wu HS, Zhang XP, Wang L, Chen WL, Chen ZL. Physiological response of Monimopetalum chinense to light stress under habitat fragmentation. Plant Soil Environ. 2010;56:551-6.

41. Dai YJ, Shen ZG, Liu Y, Wang LL, Hannaway D, Lu HF. Effects of shade treatments on the photosynthetic capacity, chlorophyll fluorescence, and chlorophyll content of Tetrastigma hemsleyanum Diels et Gilg. Environ Exp Bot. 2009:65:177-82.

42. Chazdon RL, Pearcy RW, Lee DW, Fetcher N. Photosynthetic responses of tropical forest plants to contrasting light environments. In: Mulkey SS, Chazdon RL, Smith AP, editors. Tropical forest plant ecophysiology. New York: Chapman and Hall; 1996. p. 5-55. 
43. Zhu H. A revision of the genus Lasianthus (Rubiaceae) from China. Syst Geogr Plant. 2002;72:63-110.

44. Cai ZQ, Rijkers T, Bongers F. Photosynthetic acclimation to light changes in tropical monsoon forest woody species differing in adult stature. Tree Physiol. 2005;25:1023-31.

45. Long SP, Humphries S, Falkowski PG. Photoinhibition of photosynthesis in nature. Annu Rev Plant Biol. 1994;45:633-62.

46. Kelly J, Jose S, Nichols JD, Bristow M. Growth and physiological response of six Australian rainforest tree species to a light gradient. For Ecol Manag. 2009;257:287-93.

47. Wang ML, Jiang YS, Wei JQ, Wei X, Qi XX, Jiang SY, Wang ZM. Effects of irradiance on growth, photosynthetic characteristics, and artemisinin content of Artemisia annua L. Photosynthetica. 2007;46(1):17-20.

48. Cai ZQ, Wang WH, Yang J, Cai CT. Growth, photosynthesis and root reserpine concentrations of two Rauvolfia species in response to a light gradient. Ind Crop Prod. 2009;30:220-6.

49. Schreiber U. Pulse-amplitude (PAM) fluorometry and saturation pulse method. In: Papageorgiou G, Govindjee, editors. Chlorophyll Fluorescence: a signature of photosynthesis. advances in photosynthesis and respiration series. Dordrecht: Kluwer Academic Publishers; 2004. p. 279-319.

50. Calatayud A, Roca D, Martinez PF. Spatial-temporal variations in roseleaves under water stress conditions studied by chlorophyll fluorescence imaging. Plant Physiol Biochem. 2006;44:564-73.

51. Fernandez RT, Perry RL, Flore JA. Drought response of young three apple trees on three rootstocks. II. Gas exchange, chlorophyll fluorescence, water relations, and leaf abscisic acid. J Am Soc Hortic Sci. 1997;122:841-8.

52. Baker NR. Chlorophyll fluorescence: a probe of photosynthesis in vivo. Annu Rev Plant Biol. 2008;59:89-113.

53. Mielke MS, Schaffer B. Leaf gas exchange, chlorophyll fluorescence and pigment indexes of Eugenia uniflora L. in response to changes in light intensity and soil flooding. Tree Physiol. 2009;30:45-55.

54. Wang BL, Xu M, Shi XH, Cao JH. Effects of high temperature stress on antioxidant systems, chlorophyll and chlorophyll fluorescence parameters in early cauliflower leaves. Sci Agric Sin. 2004;37:1245-50.

55. Chen JM, Yu XP, Chen JA. The application of chlorophyll fluorescence kinetics in the study of physiological responses of plants to environmental stresses. Acta Agric Zhejiangensis. 2006;18:51-5.
56. Mao LZ, Lu HF, Wang Q, Cai MM. Comparative photosynthesis characteristics of Calycanthus chinensis and Chimonanthus praecox. Photosynthetica. 2007;45(4):601-5.

57. Kitajima K, Hogan KP. Increases of chlorophyll a/b ratios during acclimation of tropical woody seedlings to nitrogen limitation and high light. Plant Cell Environ. 2003;26:857-65.

58. Björkman O, Demmig-Adams B. Regulation of photosynthetic light energy capture, conversion, and dissipation in leaves of higher plants. In: Schulze ED, Caldwell MM, editors. Ecophysiology of photosynthesis. Berlin: Springer-Verlag; 1995. p. 17-47.

59. Zhang SB, Hu H, Xu K, Li ZR, Yang YP. Flexible and reversible responses to different irradiance levels during photosynthetic acclimation of Cypripedium guttatum. J Plant Physiol. 2007;164:611-20.

60. Evans JR, Poorter H. Photosynthetic acclimation of plants to growth irradiance: the relative importance of specific leaf area and nitrogen in maximizing carbon gain. Plant Cell Environ. 2001;24:755-67.

61. Zhou J, Jian Z, Wu B, Qin P, Qi A. Physiological factors for tolerance of Kosteletzkya virginica (L.) Presl to one-instar bollworms of Helicoverpa armigera (Hubner). Acta Physiol Plant. 2010;32:519-29.

62. Li G, Wan SE, Zhou J, Yang ZY, Pei Q. Leaf chlorophyll fluorescence, hyperspectral reflectance, pigments content, malondialdehyde and proline accumulation responses of castor bean (Ricinus communis L.) seedlings to salt stress levels. Ind Crops Prod. 2010;31:13-9.

63. Meiners SJ, Pickett STA, Handel SN. Probability of tree seedling establishment changes across a forest-old field edge gradient. Am J Bot. 2002;89:466-71.

64. Tomimatsu H, Ohara M. Edge effects on recruitment of Trillium camschatcense in small forest fragments. Biol Conserv. 2004;17:509-19.

65. Renhorn KE, Esseen PA, Palmqvist K, Sundberg B. Growth and vitality of epiphytic lichens. Oecologia. 1997;109:1-9.

66. Laurance WF. Do edge effects occur over large spatial scales? Treads Ecol Evol. 2000;15:134-5.

67. Chai SF, Tang JM, Wang ML, Chen ZY, Jiang YS, Wei X. Photosynthetic and physiological characteristics of Camellia petelotii seedlings under drought stress. Acta Bot Boreal-Occident Sin. 2015:35:322-8.

68. Hu XH, Li JW, Jiang QS, Zhao RF. Responses of leaf characters of Camellia nitidissima to different light environments. Guihaia. 2010;30:355-61.

\section{Submit your next manuscript to BioMed Central and we will help you at every step:}

- We accept pre-submission inquiries

- Our selector tool helps you to find the most relevant journal

- We provide round the clock customer support

- Convenient online submission

- Thorough peer review

- Inclusion in PubMed and all major indexing services

- Maximum visibility for your research

Submit your manuscript at www.biomedcentral.com/submit
() Biomed Central 